\title{
BLOOD FLOW RATE AND CIRCUIT LIFE IN CONTINUOUS RENAL REPLACEMENT THERAPY (CRRT): A RANDOMISED CONTROLLED TRIAL (RCT).
}

Nigel Fealy ${ }^{\star} 1,2,3$, Leanne Aitken², 4, 5, Eugene du Toit 6 , Ian Baldwin 1,3 , Serigne Lo 7

1Department of Intensive Care, Austin Health, Melbourne, 2 School of Nursing and Midwifery, Griffith University, Brisbane, ${ }^{3}$ School of Nursing and Midwifery, Deakin University, Melbourne, 4 Princess Alexandra Hospital, Brisbane, Australia, ${ }^{5}$ City University London, London, United Kingdom, ${ }^{6}$ School of Medical Science, Griffith University, Gold Coast, ${ }^{7}$ Melanoma Institute of Australia, Sydney, Australia

There is minimal evidence to inform blood flow rate (BFR) during CRRT. We aimed to assess the effect of BFR on circuit life during CRRT.

A prospective RCT was conducted over one year in our tertiary ICU. Adult patients with acute kidney injury were randomised to either 150 or $250 \mathrm{mls} / \mathrm{min}$. Circuit and patient data were collected until each circuit clotted or ceased electively. Duration data for clotted circuits are presented as median (Interquartile range) and compared using the log- rank test; $p$ was set at $<0.05$. Circuit clotting data were analysed for repeated events using a hazards ratio (HR).

One hundred patients were randomised with 96 completing the study $(150 \mathrm{mls} / \mathrm{min}-49 ; 250 \mathrm{mls} / \mathrm{min}$ 47) with 462 circuits; $245: 150 \mathrm{mls} / \mathrm{min}$ and $217: 250 \mathrm{mls} / \mathrm{min}$. Median circuit life for 1 st circuit (clotted) was similar for both groups (150 mls/min: $9.1[5.5,26]$ hrs vs. $10[4.2,17] \mathrm{hrs} ; \mathrm{p}=0.37)$. Second and third circuits were also similar. $150 \mathrm{mls} / \mathrm{min}: 14[8.5,21]$ hrs vs. $13.8[8.5,16.7] \mathrm{hrs} ; \mathrm{p}=0.44 .150$ $\mathrm{mls} / \mathrm{min}: 17$ [10.5, 28.5] hrs vs.16 [12, 21.5] hrs; $p=0.52$ respectively . CRRT using $250 \mathrm{mls} / \mathrm{min}$ was not more likely to cause clotting compared to $150 \mathrm{mls} / \mathrm{min}$ (HR, $1.06[0.63,1.78] ; p=0.36$, variance of the random effect, 1.096 [0.23]). There were no differences in likelihood of clotting for: BMI, weight, vascular access type, length or site, mode of CRRT, INR or platelet count. CRRT with no use of anticoagulation was more likely to cause clotting compared to use of heparin or heparin/protamine (HR 1.61, $[1.17,2.21], p=0.002)$. Longer APTT was associated with a lower likelihood of circuit clotting (HR 0.98,[0.97, 0.99], $p=0.002)$. Clotting was more probable in males (HR $1.64[0.87,3.08] p=0.02)$.

Blood flow rate did not effect clotting during CRRT. Males and use of anticoagulation and APTT were more likely to affect circuit survival. 